\title{
Omenn Syndrome
}

National Cancer Institute

\section{Source}

National Cancer Institute. Omenn Syndrome. NCI Thesaurus. Code C61240.

An autosomal recessive combined immunodeficiency syndrome caused by mutations in the RAG-1 and RAG-2 genes. It is characterized by the presence of alopecia, erythroderma, desquamation, lymphadenopathy, and chronic diarrhea. 